University of Nebraska - Lincoln

DigitalCommons@University of Nebraska - Lincoln

Faculty Publications: Materials Research

Science and Engineering Center

Materials Research Science and Engineering

Center

2005

\title{
Nanomagnetic Structures: Fabrication and Interactions
}

David J. Sellmyer

University of Nebraska-Lincoln, dsellmyer@unl.edu

Y. C. Sui

University of Nebraska-Lincoln

Yinfan Xu

University of Nebraska - Lincoln, yxu2@unl.edu

M. L. Yan

University of Nebraska-Lincoln, myan@unlserve.unl.edu

Kory D. Sorge

University of Nebraska-Lincoln, sorge@physics.fau.edu

See next page for additional authors

Follow this and additional works at: https://digitalcommons.unl.edu/mrsecfacpubs

Part of the Materials Science and Engineering Commons

Sellmyer, David J.; Sui, Y. C.; Xu, Yinfan; Yan, M. L.; Sorge, Kory D.; and Skomski, Ralph, "Nanomagnetic Structures: Fabrication and Interactions" (2005). Faculty Publications: Materials Research Science and Engineering Center. 74.

https://digitalcommons.unl.edu/mrsecfacpubs/74

This Article is brought to you for free and open access by the Materials Research Science and Engineering Center at DigitalCommons@University of Nebraska - Lincoln. It has been accepted for inclusion in Faculty Publications:

Materials Research Science and Engineering Center by an authorized administrator of DigitalCommons@University of Nebraska - Lincoln. 


\section{Authors}

David J. Sellmyer, Y. C. Sui, Yinfan Xu, M. L. Yan, Kory D. Sorge, and Ralph Skomski 


\title{
Nanomagnetic Structures: Fabrication and Interactions
}

\author{
David J. Sellmyer, Y. C. Sui, Y. F. Xu, M. L. Yan, K. D. Sorge, and R. Skomski \\ Department of Physics and Astronomy and Center for Materials Research and Anaylsis, \\ University of Nebraska \\ Lincoln, NE 68588, USA
}

\begin{abstract}
Magnetic nanostructures with desirable properties such as monodispersed size and crystallographic texturing can be fabricated by a number of synthetic techniques. In this paper, we discuss methods for creating nanoclusters with fine control of individual propertiesand their interactions, as well as a promising chemical technique that provides control of several properties simultaneously. Current and potential applications also will be addressed.
\end{abstract}

\section{INTRODUCTION}

Nanomagnetic clusters and structures are scientifically very interesting because of the unique physical characteristics that arise at this size scale. To take advantage of these properties in applications, it is important to be able to control properties of both the particles themselves, as well as collections of particles. For example, in high-density recording, it is important for the medium to have decoupled or weakly-interacting magnetic grains that are less than $10 \mathrm{~nm}$ in size and have a very narrow size distribution. The requirement of narrow size distribution can be met by creating particles with a gas aggregation cluster deposition system [1]. Crystallographic texturing of clusters could be of great use in perpendicular magnetic recording and can readily be done by multi-layer sputter deposition and annealing [2]. Depending on the choice of matrix, the final goal of decoupled grains is achieved.

It is a difficult problem to simultaneously control all of these parameters. Chemical synthesis by a hydrogen reduction technique has high potential for controlling over each of these parameters, as well offering the ability to organize clusters in 2D arrays. In this paper, we will discuss the deposition of uniform particles by gas aggregation and the creation of textured media by sputtering and annealing. We will also discuss how hydrogen reduction of metal salts in porous alumina templates can be utilized for each of the desired properties, as well as greater control of strongly-interacting and weakly-interacting magnetic grains in the form of complex structures and isolated grains.

\section{NANOCLUSTER FABRICATION AND ORIENTATION}

\section{Monodisperse-nanocluster films}

Formation of metal clusters by gas aggregation, in which metal atoms are evaporated or sputtered into a cooled inert gas flow at relatively high pressure, has been established in several laboratories in the last decade. By repeated collisions with the carrier gas, the supersaturated metal vapor nucleates and forms clusters. The gas-aggregation methods have been applied extensively to produce small clusters of metals such as zinc, copper, and silver. In some cases this method was used in combination with a mass filter such as a quadruple or a time-of-flight 


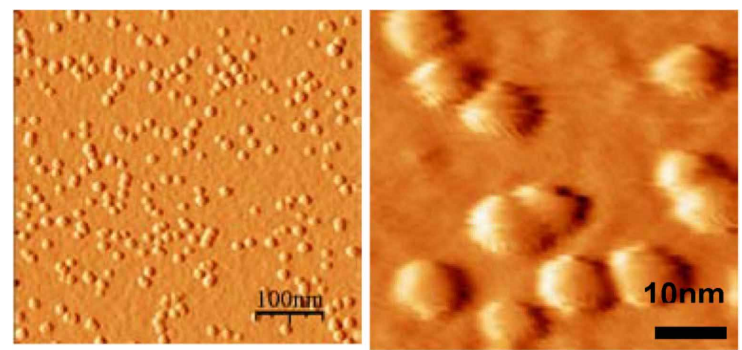

Figure 1. AFM images of Fe clusters. Right: enlarged Fe clusters with size about $8 \mathrm{~nm}$.

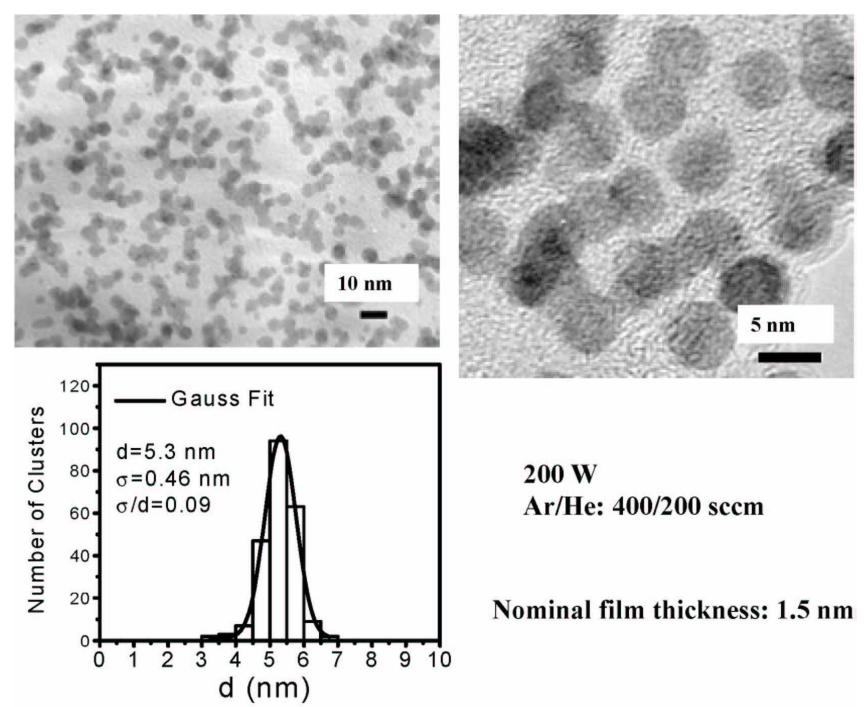

Figure 2. TEM images of FePt clusters with cluster size distribution. Right: larger magnification of the clusters.

spectrometer. The metal vapor for the cluster source can be produced by either thermal evaporation or sputter discharge [3].

The advantages of the sputtering-based cluster source are: (1) it can produce a very large range of mean cluster sizes of 200 to 15000 atoms per cluster, (2) it has a high degree of ionization from $20 \%$ to $50 \%$, depending on the target materials, and (3) a wide variety of elements and alloys can be used as source materials. Figure 1 shows an example of Fe clusters produced in such a system.

We have prepared FePt and CoPt nanoclusters which have the high-anisotropy $\mathrm{L}_{0}$ phase after annealing $[1,4,5]$. The cluster size was controlled in a range from $3 \mathrm{~nm}$ to $6 \mathrm{~nm}$ by adjusting the preparation parameters such as sputtering power, Ar-He gas flow, and gas pressure. Uniform cluster size distribution with standard deviation $\sigma / d<0.1$ is obtained. The size distribution can be further improved by employing the mass selector. Figure 2 shows the TEM image of asdeposited FePt nanoclusters. The corresponding cluster size distribution from more than 200 clusters is also included. Spherical clusters with an average size of $5.3 \mathrm{~nm}$ that fit a Gaussian distribution (with standard deviation $\sigma=0.46 \mathrm{~nm}, \sigma / d=0.09$ ) were obtained with a sputtering power of $200 \mathrm{~W}$ and Ar/He gas flow of 400/200 sccm. High resolution TEM image reveals some faceting of the FePt clusters as shown in Figure 3. This enlarged FePt cluster image shows the lattice fringes, indicating the single-crystal structure. 


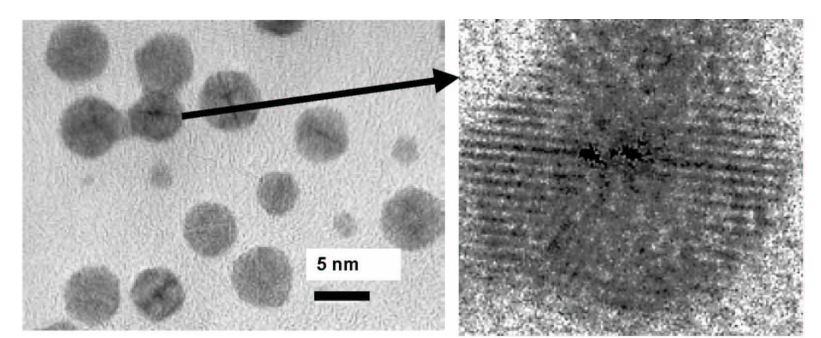

Figure 3. HRTEM images of FePt clusters with faceting. Right: an enlarged cluster showing lattice fringes.

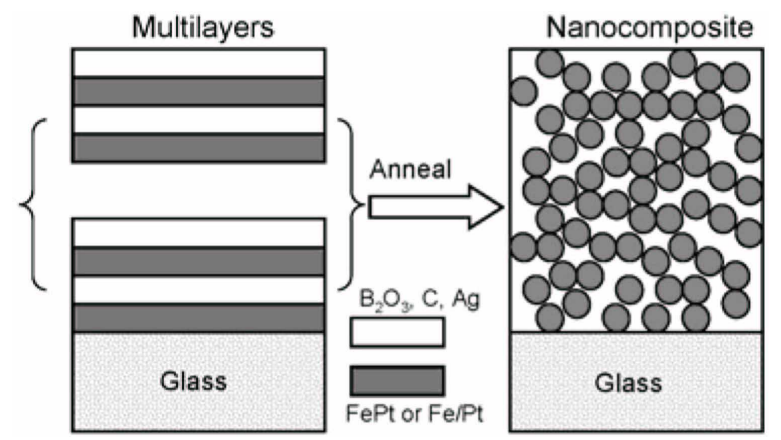

Figure 4. Preparation method of non-epitaxial growth $\mathrm{L}_{0}$-phase FePt:X nanocomposite films.

Cluster-assembled films can be fabricated by either embedding these clusters in a matrix by co-deposition or a multilayer process. The ability of the deposition technique to independently control these parameters makes it ideal for systematic studies of magnetic clusters. Recent studies on FePt:Ag cluster films suggest that the addition of $\mathrm{Ag}$ can lower the $\mathrm{L} 1_{0}$ ordering temperature and increase the coercivity significantly, but the orientation of the $\mathrm{L} 1_{0} \mathrm{FePt}$ clusters is random [5]. Magnetization reversal studies on FePt:C cluster films revealed that the thermal stability factor $K_{u} V^{*} / k_{B} T$ is higher than 100 , annealing temperature is higher than $600^{\circ} \mathrm{C}$, and the anisotropy constant $K_{u}$ is as high as $1.2 \times 10^{7} \mathrm{erg} / \mathrm{cm}^{3}[1]$.

\section{$\underline{\text { (001) orientation of non-epitaxially grown L1 }} \underline{\text { FePt:X films }}$}

While further investigations are needed for $\mathrm{L}_{0}$ FePt cluster orientation, here we discuss an alternative method of preparing oriented $\mathrm{L}_{0}$ FePt nanocomposites, the non-epitaxial growth of oriented $\mathrm{L}_{0} \mathrm{FePt}$ nanograins by multilayer deposition and annealing. Figure 4 shows the schematic initial and final structures of oriented $\mathrm{L}_{0}$ FePt:X (X $=\mathrm{Ag}, \mathrm{C}, \mathrm{B}_{2} \mathrm{O}_{3}$, etc.) films. $\mathrm{FePt} / \mathrm{X}$ or $\mathrm{Fe} / \mathrm{Pt} / \mathrm{X}$ layers were deposited individually on $\mathrm{Si}$ wafers or glass substrates by magnetron sputtering at room temperature and then annealed in vacuum for 5 to 30 minutes at various temperatures. The as-deposited multilayers become nanocomposite films with $\mathrm{L1}_{0}$-phase FePt grains embedded in a non-magnetic matrix. The orientation of the $c$ axis of the $\mathrm{L1}_{0}$-phase nanoparticles is strongly dependent on initial multilayering of $\mathrm{Fe} / \mathrm{Pt}$ as well as dimensions of the $\mathrm{Fe}, \mathrm{Pt}$, and $\mathrm{X}$ individual layers $[2,6,7]$.

Figure 5 shows the effect of $\mathrm{Ag}$ concentration on the orientation of $\mathrm{L}_{0} \mathrm{FePt}: \mathrm{Ag}$ nanocomposite films [7]. The Ag content was varied from 0 to $20 \mathrm{vol}$. \%. All the films clearly show the (001) superlattice peak, indicating that the Ag content (matrix) has a relatively small effect on orientation. 


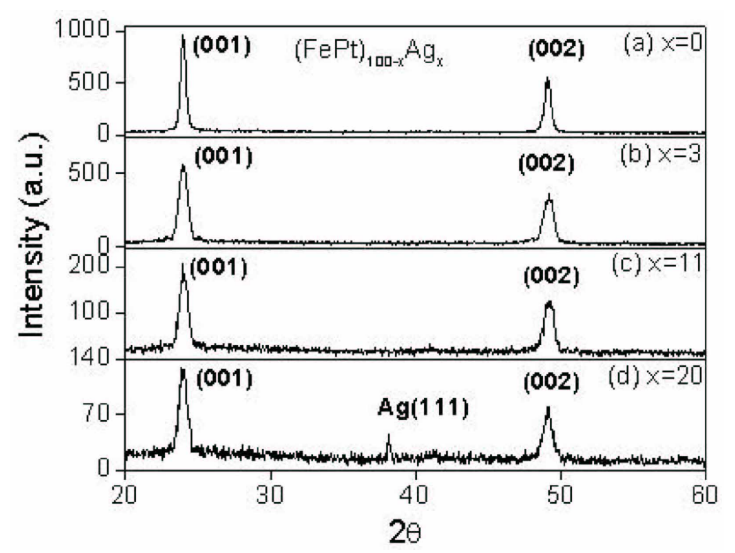

Figure 5. XRD patterns of FePt:Ag films with different Ag content. Films deposited directly on $\mathrm{Si}$ wafer and annealed at $600^{\circ} \mathrm{C}$ for 10 minutes. Film thickness is $10 \mathrm{~nm}$.

Hysteresis loops for an $\mathrm{L}_{0}$ nanocomposite $\mathrm{FePt}$ : film are shown in Figure 6. Inset are the XRD patterns of the same FePt:C film, with (001) and (002) peaks that indicate (001) orientation. The full width at half maximum (FWHM), obtained from the rocking curve of the (001) peak, is $1.68^{\circ}$ confirming a high degree of (001) texturing. The loop shows perpendicular anisotropy with square shape in the perpendicular direction due to the enhanced preferential FePt $\mathrm{L1}_{0}(001)$ texture. The perpendicular loop shows a large coercivity $\left(H_{c}=6.2 \mathrm{kOe}\right)$ and high remanence ratio $\left(M_{r} / M_{s}=0.9\right)$. The nanostructure of nonepitaxially grown $\mathrm{L1}_{0} \mathrm{FePt}: \mathrm{C}$ thin films was characterized by TEM [2]. The results show that FePt grains with uniform size less than $5 \mathrm{~nm}$ are embedded in the carbon matrix and appear to be isolated.

\section{NANOSTRUCTURE FORMATION IN ALUMINA TEMPLATES BY HYDROGEN REDUCTION}

Metal clusters also can be made by a hydrogen reduction technique in porous alumina channels [8-10]. Templates with an average pore size of $200 \mathrm{~nm}$ and a thickness of $50 \mu \mathrm{m}$ are loaded with alcohol solutions of $\mathrm{Fe}\left(\mathrm{NO}_{3}\right)_{3} \cdot 9 \mathrm{H}_{2} \mathrm{O}$ and $\mathrm{H}_{2} \mathrm{PtCl}_{6} \cdot 6 \mathrm{H}_{2} \mathrm{O}$ by a pressure cell in an Fe:Pt ratio of $1: 1$. The system is then reduced in flowing hydrogen gas at various temperatures and for various times to create particles or other more complex structures.

Hydrogen reduction in porous templates represents a one-step $\mathrm{FePt} \mathrm{L}_{0}$ cluster synthesizing

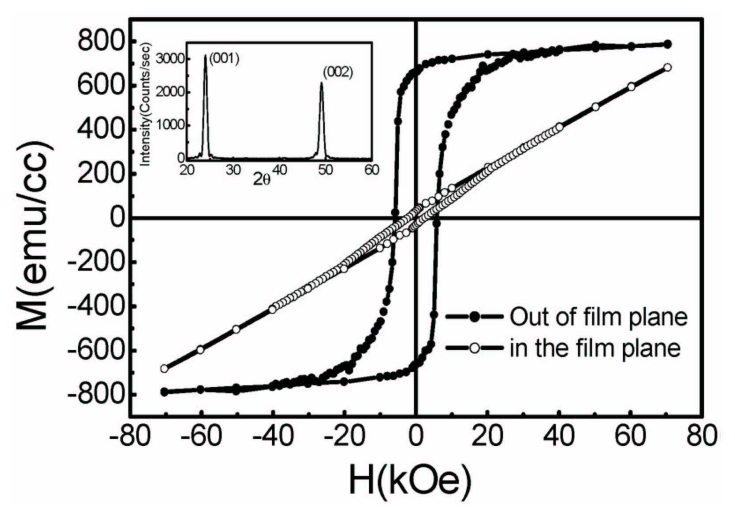

Figure 6. Hysteresis loop of FePt:C film ( $\sim 55$ vol\% FePt). Film deposited directly on $\mathrm{Si}$ wafer and annealed at $550^{\circ} \mathrm{C}$ for 5 minutes. Film thickness is $16 \mathrm{~nm}$. Inset is the XRD pattern of this sample. 


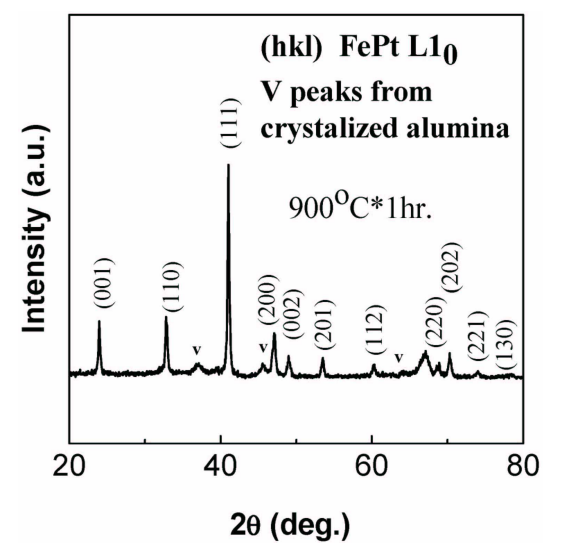

Figure 7. XRD pattern of hydrogen reduced iron nitrate and platinum chloride mixture in porous alumina films at $900^{\circ} \mathrm{C}$ for $1 \mathrm{hr}$.

technique, compared with the two-step process of solution synthesis [11,12] where first fcc FePt is created and then annealed for the transformation to the more favorable fct crystal structure. The use of porous alumina templates is preferable to other templates such as diblockcopolymers, track-etched polycarbon, porous silicon, and zeolite $[13,14]$ in hydrogen reduction because it is resistant to organic and inorganic compounds, is stable at high temperature, and can easily be removed with an aqueous sodium hydroxide solution.

\section{$\underline{\text { FePt nanoclusters }}$}

When a porous alumina film was loaded with a $1 \mathrm{M}$ iron and platinum salt alcohol solution and heated to $900^{\circ} \mathrm{C}$ in hydrogen for 1 hour, $\mathrm{FePt} \mathrm{L}_{0}$ ordered clusters were formed inside the pores. Figure 7 is the X-ray diffraction pattern of the corresponding sample. At this high treatment temperature, partial crystallization of the alumina matrix is observed.

Figure 8 is a TEM image of the FePt clusters inside the nanochannels of the template. Nearly spherical FePt nanoparticles were formed and their sizes rages from $5 \mathrm{~nm}$ to $75 \mathrm{~nm}$. The hysteresis loop of the corresponding FePt cluster assembly is shown in Figure 9, with a room temperature coercivity of $29.3 \mathrm{kOe}$. These experimental results demonstrate that this technique is a very effective approach for synthesizing $\mathrm{L} 1_{0} \mathrm{FePt}$ clusters.

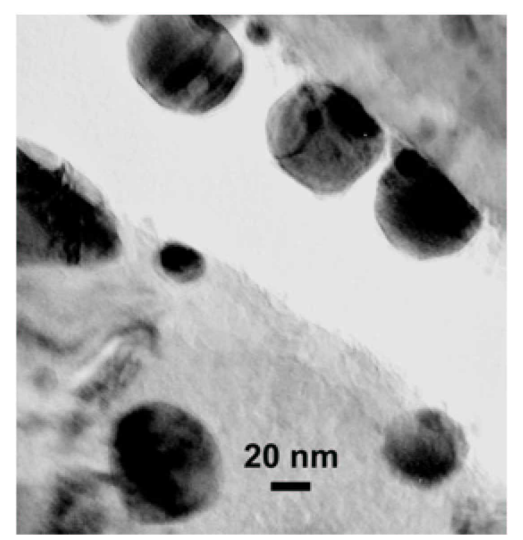

Figure 8. TEM image of the FePt clusters inside the alumina film after hydrogen reduction at $900^{\circ} \mathrm{C}$ for $1 \mathrm{hr}$. The sample is crashed in mortar and dispersed in acetone. 


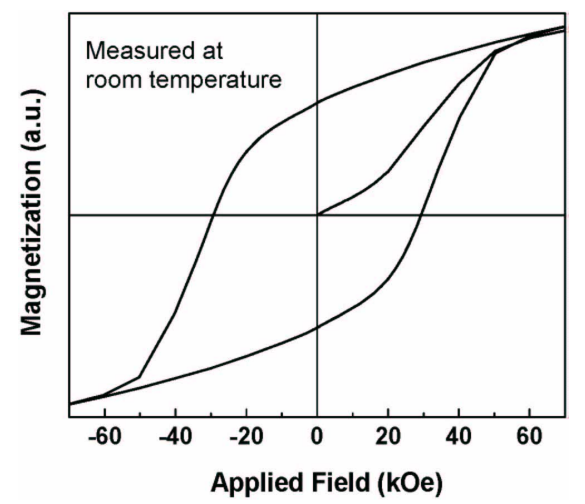

Figure 9. Hysteresis loops of the corresponding FePt cluster assembly inside the porous alumina films.

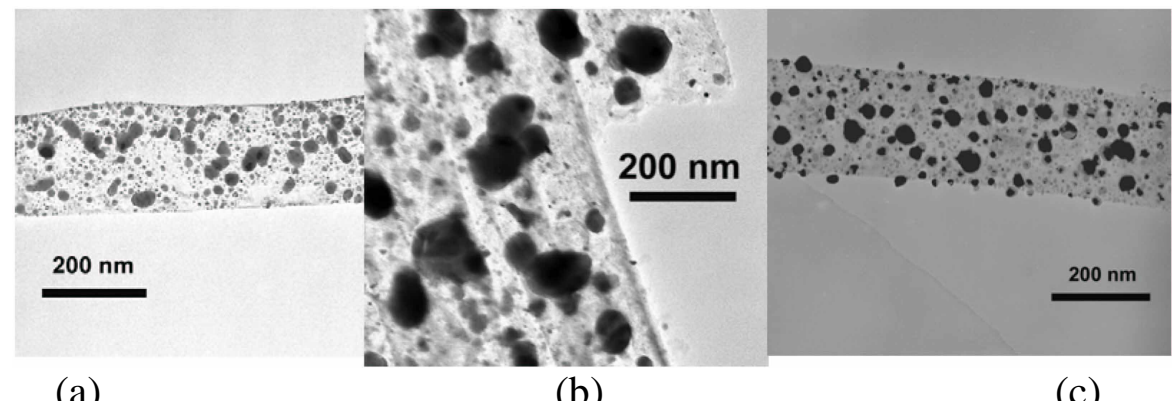

(a)

(b)

(c)

Figure 10. TEM micrographs of FePt:C composite. (a): H2-650*1 hr + CVD + N2-650*30 min. (b): H2-650*1.5 hr + H2-900*30 min + CVD. (c): H2-650*1 hr + CVD + N2-

\section{FePt: $\mathrm{C}$ composites in nanoscale channels}

When FePt clusters are annealed at high temperatures, their chemical ordering and coercivity are both very high. A serious problem caused by this high temperature processing is the agglomeration of adjacent clusters. It was found that this agglomeration was by heat-driven surface Fe and Pt diffusion. To minimize this problem, CVD is introduced to create a carbon barrier between the clusters. This will increase the activation energy for surface diffusion, and in turn, reduce the diffusion rate when heated at high temperatures.

The fabrication of FePt:C nanocomposites consists of the synthesis of FePt clusters at low temperature and the introduction of carbon by CVD [15]. After the synthesis of FePt clusters at $650^{\circ} \mathrm{C}$ for $1 \mathrm{hr}$, the flowing hydrogen was switched to high-purity nitrogen containing 3 vol \% $\mathrm{C}_{2} \mathrm{H}_{2}$ at the same temperature for $30 \mathrm{~min}$ for the deposition of carbon. $\mathrm{The}_{2} \mathrm{C}_{2} \mathrm{H}_{2}$ flow component was stopped at the end of the CVD process, while the flow of $\mathrm{N}_{2}$ was retained. The oven temperature was then increased to $900^{\circ} \mathrm{C}$ and kept constant for another 30 minutes in high-purity $\mathrm{N}_{2}$ before being cooled to room temperature.

Figure 10 shows the morphologies of the $\mathrm{FePt}: \mathrm{C}$ composite released from porous templates under TEM. The mean cluster sizes were (a) $8.7 \mathrm{~nm}$, (b) $29.9 \mathrm{~nm}$, and (c) $8.8 \mathrm{~nm}$. The data were extracted using log-normal fitting of the histogram of corresponding samples. This result indicates that the agglomeration of FePt clusters is effectively blocked by the introduction of carbon while heating at $900^{\circ} \mathrm{C}$.

Since the introduction of carbon prohibits the excessive agglomeration of FePt clusters, and reduces the exchange interaction among clusters, the coercivities of FePt:C composites are 


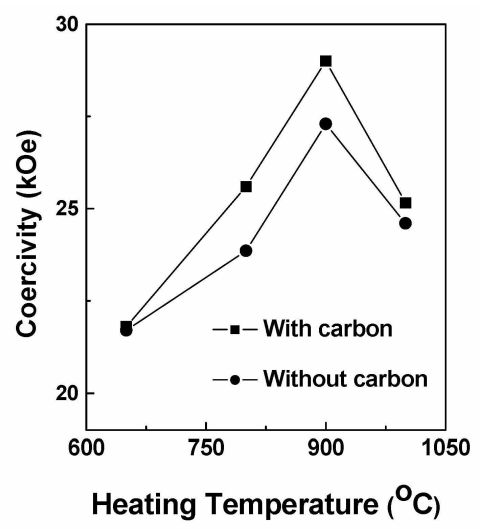

$900 * 30 \mathrm{~min}$.

Figure 11. The dependence of coercivities on annealing temperatures for FePt clusterassembly with and without carbon.

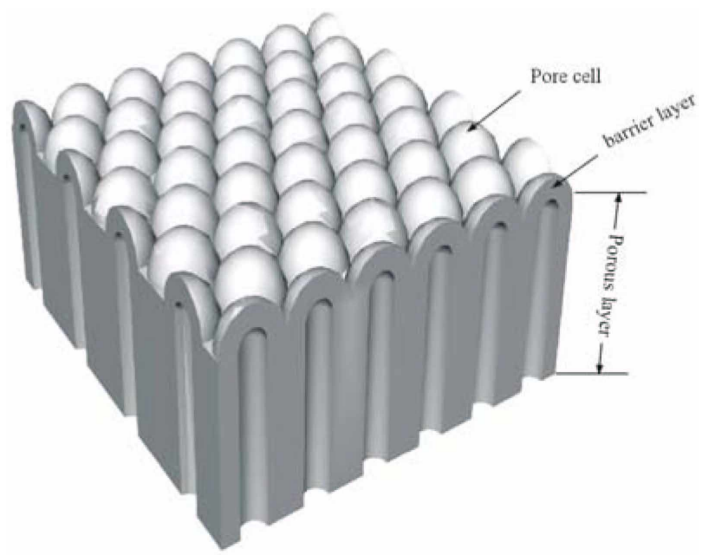

Figure 12. Illustration of the ideal structure of anodized alumina template.

higher than the FePt clusters without carbon when annealed at the same temperatures. Figure 11 shows the dependence of coercivity on the annealing temperature for clusters with and without carbon. The highest coercivity $(29.0 \mathrm{kOe})$ is reached for a FePt:C composite heated at $900^{\circ} \mathrm{C}$ for $30 \mathrm{~min}$. Further increase of the heating temperature to $1000^{\circ} \mathrm{C}$ decreases the coercivity. This may be partly caused by incoherent rotation during magnetization reversal.

Due to the confinement in the nanochannels of the template, the resulting FePt:C composite has nanofiber-like morphology. The diameter of the nanochannels inside the alumina template can be tuned from $5 \mathrm{~nm}$ to several hundred nanometers. Different magnetic clusters can be introduced by the same experimental procedure described in this paper. In this sense, quasi-onedimensional nanocomposites of carbon with different magnetic clusters can be produced. They are aligned and may find applications in magnetic nanotechnology. 


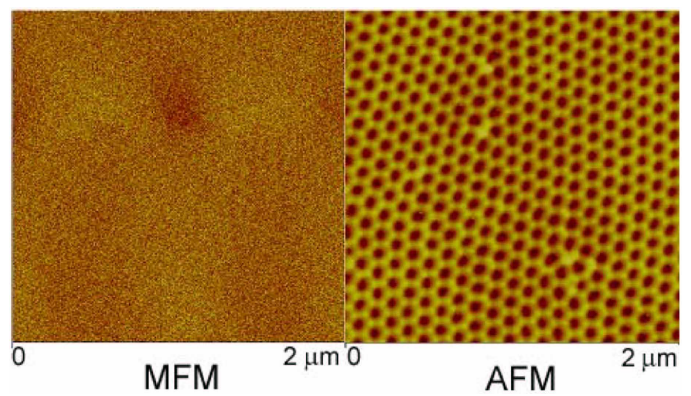

Figure 13. MFM and AFM images on the opening side of the pores after the assembly of FePt clusters under external magnetic field.

\section{Alignment of FePt nanoclusters}

It has been demonstrated that FePt clusters capped with surfactants (for example, oleic acid) will form a suspension in hexane [11]. As a suspension, they may behave as a liquid under the influence of capillary action. When the FePt $\mathrm{Ll}_{0}$ cluster suspension is drop-cast onto porous alumina templates, the clusters enter the pores because of the capillary effect. An external magnetic field applied at the same time may align these clusters during assembly.

From the illustration of the alumina template shown in Figure 12, the barrier layer consists of a regular hexagonal array of hemispherical cells above the pores. This is a generally accepted prototype of a porous alumina template. By carefully controlling the anodization process and structure of the aluminum foil, two-step anodization can create similar structures [13].

The alumina templates with a highly-ordered pore array were made by a two-step anodization process in a $0.3 \mathrm{M}$ aqueous solution of oxalic acid and at a bias of $40 \mathrm{~V}$. The pores were widened by immersing the film in a $5 \% \mathrm{H}_{3} \mathrm{PO}_{4}$ aqueous solution for 30 minutes [14]. FePt clusters were then produced by hydrogen reduction at $650{ }^{\circ} \mathrm{C}$ for 5 minutes. The clusters were released by dissolving the alumina matrix and capped with both octadecanethiol and oleic acid. After proper chemical processing, the FePt clusters with average diameter of about $11 \mathrm{~nm}$ precipitated out and were dispersed in hexane for further assembly. Figure 13 is an MFM/AFM pair obtained on the open side of the pores after the FePt clusters were assembled under an external magnetic field. From this figure the average pore diameter is about $60 \mathrm{~nm}$ and clusters entered the pores to a depth that is undetectable by the scanning magnetic tip.

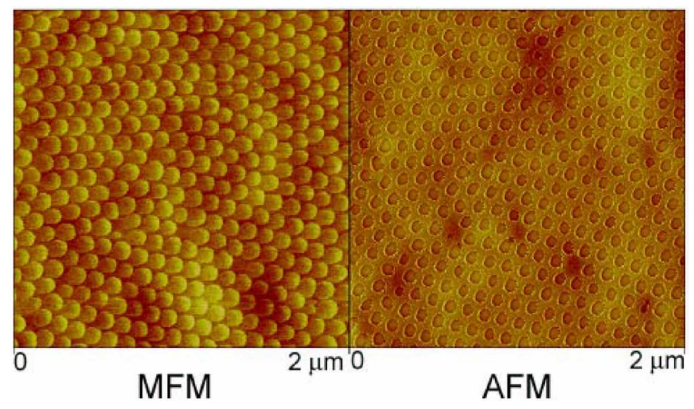

Figure 14. MFM and AFM images on the bottom of the pores after removing aluminum matrix. 


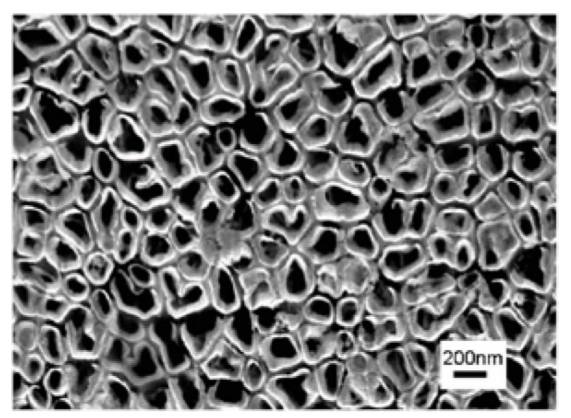

Figure 15. Scanning-electron (SEM) micrograph of an FePt sample etched in $0.3 \mathrm{M} \mathrm{NaOH}$ aqueous solution for $30 \mathrm{~min}$. It shows a closely packed FePt nanotube array grown in the pores of the template.

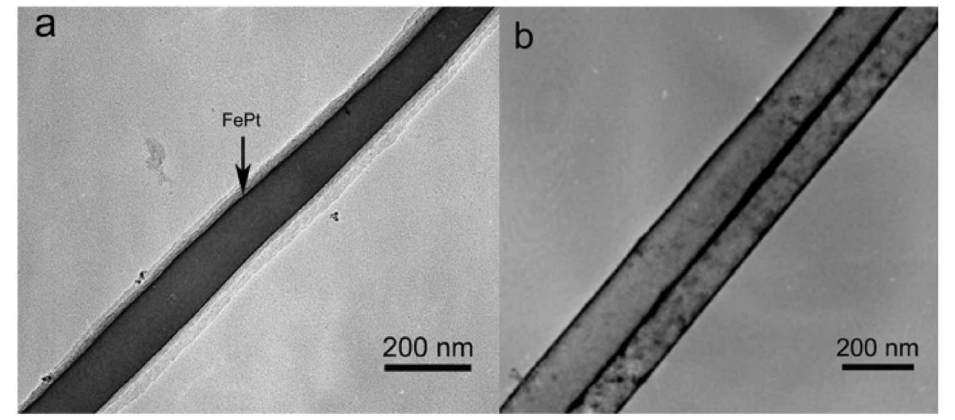

Figure 16. TEM micrographs of the magnetic nanotubes: (a) isolated composite nanotube of FePt surrounded by alumina and (b) two adjacent $\mathrm{Fe}_{3} \mathrm{O}_{4}$ nanotubes released from the matrix.

Figure 14 is another pair of MFM/AFM images from the capped end of the pores after removing the aluminum matrix. This figure demonstrates clearly that the clusters reached the bottom cap of the pores and form an ordered magnetic pattern. In other words, the cluster assembly is effectively mediated by the highly ordered array of pores

Magnetic measurement indicates that the ordered array is magnetically anisotropic. The coercivities measured parallel and perpendicular to the pores are 13.4 and $10.2 \mathrm{kOe}$ respectively. This work demonstrates that the FePt clusters can be manipulated after their synthesis, rearranged into a desired pattern, and partially oriented.

\section{$\underline{\text { FePt nanotubes }}$}

Magnetic nanotubes are very promising in applications such as magnetic recording, drugdelivery and spintronics [10, 16-18]. It has been noted that it is difficult to tune the magnetic properties of the structures with electrochemical methods [19]. This refers, in particular, to magnetic compounds, such as intermetallics and ferrimagnetic oxides used as soft and semi-hard magnets. In this section, we discuss nanotubes created by hydrogen reduction in porous alumina templates, particularly $\mathrm{L}_{0} \mathrm{FePt}$ and $\mathrm{Fe}_{3} \mathrm{O}_{4}$.

Templates loaded with a mixture of $\mathrm{H}_{2} \mathrm{PtCl}_{6} \cdot 6 \mathrm{H}_{2} \mathrm{O}$ and $\mathrm{FeCl}_{3} \cdot 6 \mathrm{H}_{2} \mathrm{O}$ were heated in hydrogen for $1.5 \mathrm{~h}$ at $560^{\circ} \mathrm{C}$ and $\mathrm{FePt}$ nanotubes formed inside the pores of the template. $\mathrm{Fe}_{3} \mathrm{O}_{4}$ nanotubes form when pores are loaded with an alcohol solution of 65 wt. $\% \mathrm{Fe}\left(\mathrm{NO}_{3}\right)_{3} \cdot 9 \mathrm{H}_{2} \mathrm{O}$ and heated in air, followed by processing at $250^{\circ} \mathrm{C}$ for $2.5 \mathrm{hr}$ in flowing hydrogen.

Figure 15 is an SEM micrograph showing the FePt tubes after slight etching. The white deformed donut shapes are FePt, indicating that close-packed nanotubes were formed inside the pores. A likely explanation for the somewhat asymmetrical cross section of the tube ends is that 


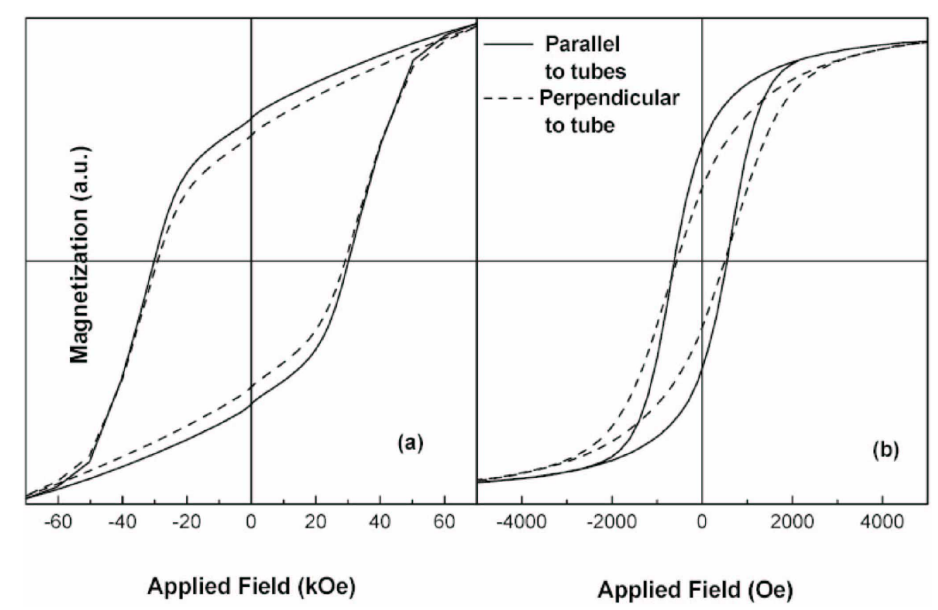

Figure 17. Hysteresis loops measured at $300 \mathrm{~K}$ : (a) $\mathrm{FePt}$ and (b) $\mathrm{Fe}_{3} \mathrm{O}_{4}$. The external field is parallel (solid lines) and perpendicular (dashed lines) to the tubes axes.

the templates were mounted on a sample holder with pores horizontal. As a consequence, the liquid Fe and Pt chloride mixture near the pore openings may tend to flow out of the tubes and accumulate during heating in hydrogen before reduction.

Figure 16 (a) shows a TEM image of the FePt tube, encased in alumina, taken after etching for 50 min and dispersing in acetone. The chemical bond between the interface of the FePt alloy and the inner walls of the nanochannels allows the formation of nanotubes rather than clusters [20]. Figure 16 (b) shows two adjacent $\mathrm{Fe}_{3} \mathrm{O}_{4}$ nanotubes after removal of the alumina matrix.

Figure 17 shows room-temperature hysteresis loops of $\mathrm{FePt}(\mathrm{a})$ and $\mathrm{Fe}_{3} \mathrm{O}_{4}(\mathrm{~b})$, measured by SQUID magnetometry parallel (solid lines) and perpendicular (dashed lines) to the tube axes. While sharing some basic characteristics of magnetic hysteresis loops, the two curves exhibit two striking differences. First, the coercivity of the FePt nanotubes is about $20.9 \mathrm{kOe}$, much larger than the $\mathrm{Fe}_{3} \mathrm{O}_{4}$ nanotube coercivity of $0.61 \mathrm{kOe}$. Second, the difference between the parallel and perpendicular curves is much more pronounced for the oxide tubes. Both features are related to the magnitudes of the magnetocrystalline anisotropy of the two compounds-about $6.6 \times 10^{7}$ $\mathrm{erg} / \mathrm{cm}^{3}$ for $\mathrm{L}_{0} \mathrm{FePt}$ and $-1.1 \times 10^{5} \mathrm{erg} / \mathrm{cm}^{3}$ for $\mathrm{Fe}_{3} \mathrm{O}_{4}$.

Magnetic nanotubes may provide magnetic field sources at the nanoscale for nanoelectromechanical system (NEMS) [21]. Halbach cylinders create a homogeneous cavity field which is, in general, larger than the saturation magnetization of the material. Similar configurations exist for higher-order fields, such as quadrupole fields [22]. If templates with an ordered pore structure were employed, ordered arrays of magnetic nanotubes could be fabricated for use as non-volatile memory [18].

\section{SUMMARY}

In this paper, we have demonstrated a variety of synthetic techniques used for controlling properties of nanoscale magnetic structures. Gas aggregation cluster deposition is a powerful technique for making monodisperse metal clusters. Crystallographic texturing of films can be achieved by multilayer sputtering followed by annealing. Hydrogen reduction of metal salts in porous alumina templates is a useful technique for controlling many of these properties simultaneously and making either isolated particles or structures that require strong interactions such as nanotubes. 


\section{ACKNOWLEDGMENTS}

This work was supported by the U.S. Department of Energy, the NSF-MRSEC program, the Army Research Office, the Information Storage Industry Consortium, the W. M. Keck Foundation, and the Nebraska Research Initiative.

\section{REFERENCES}

1. Y. Xu, M. L. Yan, D. J. Sellmyer, IEEE Trans. Magn. 40, 2525 (2004).

2. M. L. Yan, X. Z. Li, L. Gao, S. H. Liu, D. J. Sellmyer, R. J. M. van de Veerdonk, and K. W. Wierman, Appl. Phys. Lett., 83, 3332 (2003).

3. For a review and references, see: D. J. Sellmyer, C. P. Luo, Y. Qiang, and J. P. Liu, in Handbook of Thin Film Materials vol. 5, edited by H. S. Nalwa (Academic Press, New York, 2002), p. 337.

4. Y. Xu, Z. G. Sun, Y. Qiang and D. J. Sellmyer, J. Magn. Magn. Mater. 266, 164 (2003).

5. Y. Xu, Z.G. Sun, Y. Qiang and D.J. Sellmyer, J. Appl. Phys. 93, 8289 (2003).

6. H. Zeng, M. L. Yan, N. Powers and D. J. Sellmyer, Appl. Phys. Lett. 80, 2350 (2002).

7. Y. Shao, M. L. Yan and D. J. Sellmyer, J. Appl. Phys. 93, 8152 (2003).

8. D. J. Sellmyer, M. Zheng, R. Skomski, J. Phys.:Condens. Matter. 13, R433 (2001).

9. Y. C. Sui, D. R. Acosta, J. A. González-León, A. Bermúdez, J. Feuchtwanger, B. Z. Cui, J. O. Flores, and J. M. Saniger, J. Phys. Chem. B. 105, 1523 (2001).

10. Y. C. Sui, R. Skomski, K. D. Sorge, and D. J. Sellmyer. Appl. Phys. Lett. 84, 1525 (2004).

11. H. Zeng, J. Li, J. P. Liu, Z. L. Wang, and S. S. Sun, Nature 420, 395 (2002).

12. D.J. Sellmyer, Nature 420, 374 (2002).

13. Y. C. Sui, B. Z. Cui, L. Martinez, R. Perez, and D. J. Sellmyer, Thin Solid Films 406, 64 (2002).

14. Y. C. Sui, and J.M. Saniger, Mater. Lett. 48, 127 (2001).

15. Y. C. Sui, B. Z. Cui, R. Guardian, D. R. Acosta, R. Perez, and L. Martinez, Carbon 40, 1011 (2002).

16. S. Khizroev, M. H. Kryder, D. Litvinov, and D. A. Thompson, Appl. Phys. Lett. 81, 2256 (2002).

17. A. S. Goldstein, M. H. Gelb, and P. J. Yager, J. Control. Release 70, 125 (2001).

18. R. P. Cowburn, D. K. Koltsov, A. O. Adeyeye, M. E. Welland, and D. M. Tricher, Phys. Rev. Lett. 83, 1042 (1999).

19. G. Tourillon, L. Pontonnier, J. P. Levy, and V. Langlais, Electrochemical and Solid-State Lett. 3, 20 (2000).

20. S. A. Chambers, T. Droubay, D. R. Jennison, T. R. Mattsson, Science 297, 827 (2002).

21. M. Zahn, J. Nanoparticle Res. 3, 73 (2001).

22. R. Skomski and J. M. D. Coey, Permanent Magnetism, (Institute of Physics, Bristol 1999) p. 313. 